\title{
SUNKIŲ LIGONIŲ GYDYMAS ANTIBIOTIKAIS
}

\author{
ARVYDAS VALAVIČIUS
}

KLAIPĖDOS UNIVERSITETINĖS LIGONINĖS PULMONOLOGIJOS SKYRIUS

\begin{abstract}
Reikšminiai žodžiai: infekcija, antibiotikai, gydymas antibiotikais, antibiotikų dozavimas, antibiotikų skvarbumas, pneumonija, pūlinès ligos.

Santrauka. Antibiotikais gydant sunkius ligonius, reikia tam tikru, gilesnių žinių. Dažnai j̇vairiomis sunkiomis ligomis sergančius ligonius pražudo ne pagrindinè liga, o jos infekcinės komplikacijos, iš kurių dažniausia plaučių uždegimas. Straipsnyje aptariama antibiotikų jisiskverbimas į audinius, veikimo mechanizmai, pagrindinès antibiotiku grupès ir pagrindiniai gydymo taikiniai.
\end{abstract}

\section{POVEIKIO MECHANIZMAS}

Antibiotikai slopina bakterijų dauginimąsi, veikdami jų sienelès baltymų sintezę ir kitus metabolinius procesus. Antibiotikų skirstymas ì baktericidinius ir bakteriostatinius nèra tikslus, nes antibiotikai vienus bakterinius agentus gali veikti baktericidiškai, o kitus - bakteriostatiškai. Baktericidiniai antibiotikai žudo bakterijas, slopindami ląstelių sienelių sintezę ar nutraukdami organizmų metabolinius procesus. Tokiems antibiotikams priklauso penicilinai, cefalosporinai, aminoglikozidai, fluorchinolonai, vankomicinas, rimfampicinas ir metronidazolis. Bakteriostatiniai antibiotikai slopina bakterijų dauginimąsi, bet neveikia bakterijų sienelių sintezès. Jiems priklauso makrolidai, tetraciklinai, sulfanilamidai, chloramfennikolis, klindamicinas.

Gydant plaučių ligas, veiksmingas gali būti bet kuris antibiotikas, o gydant infekcini endokarditą, osteomielitą, meningitą, taip pat, kai yra neurotropenija, baktericidiniams vaistams teikiama pirmenybè.

Antimikrobini efektyvumą apibrèžia minimali inhibicine koncentracija (MIK, angl. MIC) ir minimali baktericidinè koncentracija (MBK, angl. $M B C$ ). MIK mažiausia antibakterinio preparato koncentracija, kuri nuslopina 90 proc. bakterijų kolonijų augimą standartinėse terpèse. MBK - mažiausia koncentracija, kuri turi susidaryti, kad kolonijų skaičius standartinèje terpèje sumažètų 3 kartus (sunaikinama 99,9 proc.). Vis dèlto gydytojas negali pasikliauti vien MIK ir MBK duomenimis, neatsižvelgęs, kaip agentas patenka ì plaučius (1 lentelè). MIK rodo mikroorganizmo jautrumą antibi- otikui in vivo, bet plaučiuose gali susidaryti mažesnè koncentracija negu serume, taigi ir vaisto poveikis bus silpnesnis arba jo išvis nebus.

Kai yra ryšys tarp vaisto koncentracijos kraujyje ir MIK, galima tikètis nugalèti mikroorganizmą. Gydant kai kuriais vaistais (pavyzdžiui, beta laktaminiais antibiotikais), kraujyje tam tikrą laiką reikia palaikyti pakankamą koncentraciją, kad būtų paveiktos bakterijos. Jeigu koncentracija dideja greitai, antibiotikuc veiksmingumas mažeja. Teoriškai būtų optimalu taikyti ilgalaikę infuziją. Kitų vaistų (chinolonų, aminoglikozidų) efektyvumą lemia greitai susidaranti vaisto koncentracija, kuri gali sunaikinti bakterijas, kraujyje ar audiniuose. Po to jų efektyvumas sumažeja. Tokių vaistų skiriama vieną kartą per parą maksimalia doze (artima toksinei).

1 lentelè. ANTIBIOTIKŲ I SISKVERBIMAS ! KVĖPAVIMO TAKŲ SEKRETĄ

Riebaluose tirpūs, koncentracija nepriklauso nuo

uždegimo, gerai įsiskverbia

- Chinolonai

- Naujieji makrolidai: azitromicinas, klaritromicinas

- Tetraciklinai

- Klindamicinas

- Trimetoprimas/sulfametksazolis

- Linezolidas

Santykinai riebaluose netirpūs, nuo uždegimo priklausoma koncentracija plaučiuose, blogai įsiskverbia

- Aminoglikozidai

- Beta laktaminiai vaistai

- Penicilinai

- Cefalosporinai

- Monobaktamai

- Karbapenemai 


\section{ISISKVERBIMO I AUDINIUS PROBLEMA}

Antibiotikų koncentracija plaučiuose priklauso nuo kraujotakos infekcijos vietoje, antibiotiku jungimosi su baltymais laipsnio ir antibiotikų pernašos i plaučius aktyvumo. Svarbu ir mikroorganizmo buvimo vieta, pavyzdžiui, netipinių infekcijų (Chlamidia, Legionella) atveju geriausia eradikacija pasiekiama, kai gydoma vaistais, kurių didelè koncentracija susidaro makrofaguose. Antibiotikai gali prasti veiklumą tam tikromis sąlygomis, pavyzdžiui, rūgštinèje terpẻje, kokia būdinga plaučiuose, esant pūlinei infekcijai, nustoja veikti aminoglikozidai. Bakterijos gali gaminti beta laktamazes, kurios inaktyvuoja daugumą penicilinų ir cefalosporinų. Bakterija gali tapti atspari vaistui (jai sunaikinti reikalingos didelès ir sunkiai lokaliai pasiekiamos vaistų koncentracijos), nes jų apvalkalas pasidaro atsparus antibiotiku skverbimuisi.

\section{ANTIBIOTIKAI}

\section{Beta laktaminiai antibiotikai}

Šią grupei priklauso antibiotikai, kurie turi beta laktamini žiedą (penicilinų - sudarytas iš 5 tiazolidinių žiedų, cefalosporinų - iš šešių dihidrotiazidinių žiedų). Modifikuojant tiazolidini žiedą sukurti penemai (imipenemas ir meropenemas), monobaktamai (aztreonamas) neturi antro žiedo. Šie vaistai gali būti derinami su beta laktamaziu inhibitoriais (sulbaktamu, tazobaktamu ar klavulano rūgštimi). Beta laktaminiai antibiotikai veikia slopindami bakterijų sienelių peptidoglikanų sintezę.

Penicilinams priklauso natūralūs penicilinai (penicilinas G ir penicilinas V), aminopenicilinai (ampicilinas ir amoksicilinas), antistafilokokiniai penicilinai (oksacilinas), antipseudomoniniai preparatai bei juc deriniai su beta laktamaziu inhibitoriais. Antipseudomoniniams penicilinams priklauso senieji karbopenicilinai (tikarcilinas) ir ureidopenicilinai (piperacilinas, azlocilinas bei mezlocilinas), kurie kartu su piperacilinu ir azlocilinu yra aktyviausiai veikia Pseudomonas aeruginosa. Cefalosporinų yra keturių kartų. Ankstyvesnieji (cefazolinas, cefradinas, cefaloksinas, cefaleksinas, cefalotinas) geriausiai veikia gramteigiamus organizmus, bet beveik neveikia daugumos gramneigiamų infekcijų ir anaerobų. Jie yra labai jautrūs beta laktamazių poveikiui. Naujausios kartos cefalosporinams būdingas platesnis poveikis bei didesnis atsparumas beta laktamazių poveikiui. Antros kartos cefalosporinai (cefuroksimas, cefamandolis, cefakloras), beveik vienodai veikia gramneigiamas ir gramteigiamas bakterijas, yra atsparūs beta laktamazėms. Trečios kartos vaistai (ceftriaksonas ir cefotaksimas veiksmingi naikinant penicilinui atsparius pneumokokus, o ceftazidimas - Pseudomonas aeruginosa. Jie geriau veikia gramneigiamas bakterijas bei šiek tiek veikia anaerobus. Ketvirtos kartos cefalosporinas cefepimas stipriai veikia pneumokokus ir Pseudomonas bei sąlygoja mažesnị Enterobacter atsparumą.
Imipenemas ir karbepenemas yra plataus poveikio antibiotikai, veikiantys gramteigiamus, gramneigiamus (iskaitant ir Pseudomonas) organizmus bei anaerobus. Imipenemą inkstuose suardo fermentas dehidropeptidazè. Jis vartojamas tik kartu su cilastinu, kuris slopina minètąji fermentą. Monobaktamai (aztreonamas) gali būti vartojami alergijos penicilinui atvejais. Jie efektyvūs tik gydant gramneigiamų mikroorganizmų sukeltas infekcijas (taip pat ir Pseudomonas).

\section{Fluorchinolonai}

Šie baktericidiniai antibiotikai veikia bakterijų DNR girazę, DNR sintezę, atsikūrimą ir transkripciją bei kitus ląstelinius procesus. Skiriant chinolonus, siekiama, kad staiga susidarytų didele koncentracija.

Plaučių infekcijų atveju svarbūs du chinolonų bruožai. Pirma, jie gerai skverbiasi i plaučių sekretą bei uždegimo ląsteles, taigi susidaro didesnè koncentracija negu serume. Šie preparatai kliniškai gali būti efektyvesni, negu galima tikètis pagal MIK. Antra, ir geriamųjų jų bioprieinamumas yra didelis. Tai svarbu gydant plaučių uždegimą namuose slaugomiems ligoniams. Gydant stacionare, ši savybẻ leidžia greičiau pereiti nuo intraveninių vaistų prie geriamųjų, tuo pačiu sutrumpinti gulejimo stacionare laiką.

Pirmos kartos chinolonai veikia gramneigiamą florą ir vartojami daugeliui šlapimo takų infekcijų gydyti (pvz., nalidiksinè rūgštis). Gramteigiamus mikroorganizmus veikia antros kartos chinolonai: ciprofloksacinas, ofloksacinas, flerofloksacinas, lomefloksacinas. Tačiau galimybės jais gydyti plaučių infekciją yra ribotos, nes dèl aukštos MIK pneumokokui paveikti reikia didelių terapinių dozių. Trečios kartos agentai pasižymi dar stipresniu poveikiu gramteigiamai florai, ypač pneumokokui. Šiu vaistu grupei priklauso vadinamieji naujieji fluorchinolonai: levofloksacinas, gatifloksacinas, gemifloksacinas, moksifloksacinas. Veiksmingiausias gydant pneumokokinę infekciją yra gemifloksacinas. Naujųjų preparatų veikimo pusperiodis yra ilgas, todèl jie vartojami vieną kartą per parą.

\section{Aminoglikozidai}

Šie baktericidiniai preparatai veikia bakterijų baltymų sintezę esant gramneigiamai florai ir dažniausiai vartojami kartu su kitais preparatais gydant sunkias gramneigiamų organizmų, kaip antai Pseudomonas aeruginosa, sukeltas ligas. Derinant su beta laktaminiais antibiotikais, pasireiškia ju sinerginis poveikis. Amikacinas pats atspariausias fermentu poveikiui, o tobramicinas yra dar efektyvesnis gydant pseudomonines infekcijas. Aminoglikozidai blogai prasiskverbia ị plaučių audini, jų veiklumas gali nuslopti dèl padidejjusio $\mathrm{pH}$ uždegimo apimtoje plaučių dalyje. Vaistų derinys nèra efektyvesnè pseudomoninès infekcijos profilaktikos priemonè nei vienas beta laktaminis antibiotikas. Tuo tarpu bakterieminę pseudomoninę infekciją gydyti šių grupių vaistų deriniu yra veiksmingiau. 
Aminoglikozidai veikia didelès koncentracijos principu ir yra vartojami vieną kartą per parą. Taip optimizuojamas efektyvumas ir sumažinamas toksiškumas. Turi būti stebima inkstų funkcija ir vaistų koncentracija kraujyje.

\section{Oksazolidonai}

Didelè ligoninių, kur ilgai gydomi sunkūs, komplikuoti ligoniai, problema - meticilinui atsparūs auksiniai (ir pagal pavadinimą, ir pagal kainą, kurią tenka sumokèti ligoninèms) stafilokokai. Nors jis tebèra jautrus vankomicinui, bet pasaulyje jau randasi pranešimu apie ir šiam antibiotikui atsparias padermes.

Linezolidas yra naujos oksazolidonų klasės antibiotikas. Jis slopina bakterijų baltymų sintezę. Veikia ribosomas ir neleidžia susiformuoti ląstelès RNR. Dèl unikalaus vaisto poveikio mechanizmo néra kryžminio atsparumo.

Linezolidas efektyviai veikia meticilinui atsparu auksini stafilokoką ir vankomicinui atsparius $E$. Coli, Enterococcus faecalis ir faecium, anaerobus (Clostridium spp. Corynebacterium spp., Clostridium perfringers, Bacteroides fragils, Peptostreptococcus spp., Prevotella spp.) ir gramteigiamas lazdeles (Corynebacterium spp., Lysteria monocytogenes, tuberkuliozès mikobakterijas). In vitro jam jautri ir kita kvejpavimo taku patogeninè flora.

Daugelị bakterijų šie antibiotikai veikia bakteriostatiškai, o pneumokokus, bakteroidus ir kitus - baktericidiškai. Rekomenduojama MIK gydant daugumos patogenų sukeltas ligas yra mažiau kaip $4 \mathrm{mg} / \mathrm{L}$. Paros dozè - 600 mg per 2 kartus. Preparatas labai gerai pasisavinamas. Pakankama koncentracija kraujyje susidaro vaistą ir geriant, ir leidžiant i veną. Gyvavimo pusperiodis - 4,5-5,5 val. Didžiausia koncentracija suvartojus $600 \mathrm{mg}-18 \mathrm{mg} / \mathrm{L}$. Nereikia keisti doziuc esant inkstų nepakankamumui.

Antibiotikas veiksmingas gydant hospitalinę ir visuomeneje igytą pneumoniją, komplikuotas poodžio infekcines ligas, sepsị.

Šalutinių reiškinių pasitaiko retai, vaistas gerai toleruojamas. Kartais būna pykinimas, diarejja, anemija bei trombocitopenija (jeigu vartojama ilgiau).

\section{Taisyklingas dozavimas}

Kad antibiotikai būtų tinkamai vartojami, reikia įvertinti jų dozavimo ypatumus, veikimo mechanizmą, kiekvienam patogenui reikalingą santykinę MIK, ir jo ìsiskverbimą ì židinị. Kad mikrobas būtų eradikuotas, tam tikrą laiką būtina antibiotiko MIK. Beta laktaminių antibiotikų ir vankomicino efektyvumas priklauso nuo to, kiek laiko tinkama koncentracija laikosi kraujyje. Tačiau vaistų koncentracija serume - dar ne viskas. Chinolonų, makrolidu ir linezolido koncentracija plaučių audinyje būna didesnè negu kraujyje, o beta laktaminiai antibiotikai ir vankomicinas i plaučiuc au- dini patenka sunkiau: jų koncentracija kraujyje būna didesnè negu audinyje. Chinolonu ir makrolidu esant plaučių infekcijoms galima skirti vartoti mažesnėmis dozėms, o gydant beta laktaminiais antibiotikais bei vankomicinu - atvirkščiai. Teoriškai būtų gerai skirti šiuos antibiotikus infuzijos būdu, tačiau kol kas nèra patvirtinta, kad tai būtų praktiškai naudinga.

Rekomenduojamas antibiotikų dozavimas nurodytas 2 lentelèje.

\section{ANTIMIKROBINIO GYDYMO EIGA}

Svarbu pradèti gydymą plataus poveikio antibiotikais, o vèliau, gavus mikrobiologinių pasèlių duomenis, gydyti pagal sukèlèją ir jo jautrumą. Tai vadinamoji deeskalacija (angl. deescalation) - pradedama nuo plataus poveikio, o paskui skiriama siauro poveikio tikslinių preparatų. Intensyviosios terapijos skyriuose sudètinis gydymas gali būti skirtas įsitikinus, kad flora atspari gydymui, pavyzdžiui, Pseudomonas aerugino$s a$ ar mišri infekcija. Visada reikia stengtis skirti kuo tiksliau ir geriau veikiančius preparatus. Diskutuojama dèl optimalios gydymo trukmès.

\section{Empirinis gydymas}

Empirinis gydymas turi būti paskirtas nelaukiant galutinių tyrimų rezultatų. Empirinis gydymas reikalingas dèl šių priežasčių:

- diagnozè nenustatoma iki pusès pneumonijos atvejų;

- sunkios pneumonijos atvejais sukèlejjai nuspèjami dar nesant mikrobiologinių tyrimų rezultatų;

- atsižvelgiant i lydinčias ligas, adekvatus empirinis gydymas duoda gerų rezultatų.

Tai tinka ir hospitalinės pneumonijos atvejais, nes:

- klinikiniai kriterijai labai jautrūs ir specifiški;

- remiantis vietiniais gydymo algoritmais, galima paskirti tinkamą gydymą;

- vaistus galima iš karto keisti gavus trachèjos aspirato ar skreplių pasėlių duomenis.

2 lentelè. REKOMENDUOJAMOS VAISTU PAROS DOZĖS GYDANT KRITIŠKAI SUNKIUS LIGONIUS, KURIU INKSTU VEIKLA NORMALI

\section{Beta laktaminiai}

Cefepimas $-1-2 \mathrm{~g}$ kas $8-12$ val.

Ceftazidimas $-2 \mathrm{~g}$ kas 8 val

Ceftriaksonas $-1-2 \mathrm{~g}$ kas 1, 2 kartus per parą.

Imipenemas $-1 \mathrm{~g}$ kas $8 \mathrm{val}$. arba $500 \mathrm{mg}$ kas $6 \mathrm{val}$

Meropenemas $-1 \mathrm{~g}$ kas $6-8 \mathrm{val}$.

Piperacilinas/tazoktamas $-4,5 \mathrm{~g}$ kas $6 \mathrm{val}$

\section{Aminoglikozidai}

Gentamicinas, tobramicinas $-7 \mathrm{mg} / \mathrm{kg}$

Amikacinas - $20 \mathrm{mg} / \mathrm{kg}$

Antistafilokokiniai preparatai (esant meticilinui atspariam stafilokokui)

Vankomicinas - $15 \mathrm{mg} / \mathrm{kg}$ kas 12 val.

Linezolidas - $600 \mathrm{mg}$ kas $12 \mathrm{val}$

\section{Chinolonai}

Ciprofloksacinas $-400 \mathrm{mg}$ kas 8 val.

Levofloksacinas - $750 \mathrm{mg}$ per dieną. 


\section{Sunki visuomenèje igyta pneumonija}

Ligoniams, sergantiems sunkia pneumonija, būtina skirti intraveninių antibiotiku, kurie veiktu 3 svarbiausius patogenus (S. pneumoniae, H. influenzae, Legionella pneumophilla).

Kaip pirmaeiliai vaistai rekomenduojami fluorchinolonai arba makrolidai kartu su beta laktaminiu antibiotiku. Monoterapija makrolidais taikoma tik atskirais atvejais. Kadangi pas mus dar nèra intraveninių chinolonų, pirmiausia pasirenkamas makrolido ir beta laktaminio antibiotiko derinys. Tačiau praktiškai dažnai pakanka ir antros ar trečios kartos cefalosporino, nes penicilinui atsparių pneumokokų Lietuvoje mažai.

Anksčiau aptartas empirinis gydymas bus neefektyvus, jeigu ligą sukèlè auksinis stafilokokas. Sunkios pneumonijos atvejais šis sukèlejjas nustatomas retai, dažniau esant cukriniam diabetui, inkstų nepakankamumui ar po gripo. Stafilokokinè infekcija tikètina, jei ligonis - intraveninių narkotikų vartotojas, jiems dažnai pasitaiko stafilokokinis sepsis.

Kitas nepasiduodantis įprastiniam gydymui mikroorganizmas - Pseudomonas aeruginosa. Gramneigiamų bakterijų radimas trachejos išplovose, skrepliuose leidžia ịtarti pseudomoninę infekciją. Ji tikètina, jeigu yra kliniškai reikšmingų struktūrinių plaučių pokyčių, pavyzdžiui, bronchektazių, ypač jeigu jau anksčiau buvo išskirta Pseudomonas. Tokiais atvejais sunkiai pneumonijai gydyti rekomenduojamas antipneumokokinis antipseudomoninis beta laktaminis antibiotikas (piperacilinas/tazobaktamas, cefepimas, imipenemas, meropenemas) (3 lentelè) kartu su ciprofloksacinu ar levofloksacinu. Kitas derinys - beta laktaminis vaistas, aminoglikozidas ir fluorchinolonas. Praktiškiau ir prieinamiau pagal kainą būtų derinti beta laktamini preparatą (ceftazidimą) su aminoglikozidu (gentamici- nu, amikacinu) ir makrolidu (azitromicinu, klaritromicinu). Reikia turèti omenyje, kad šie deriniai taikomi empiriniam sunkios pneumonijos gydymui, kai, be tipiniuc patogenų, tikimasi ir pseudomoninès infekcijos.

3 lentelè. ANTIPSEUDOMONINIAI ANTIBIOTIKAI

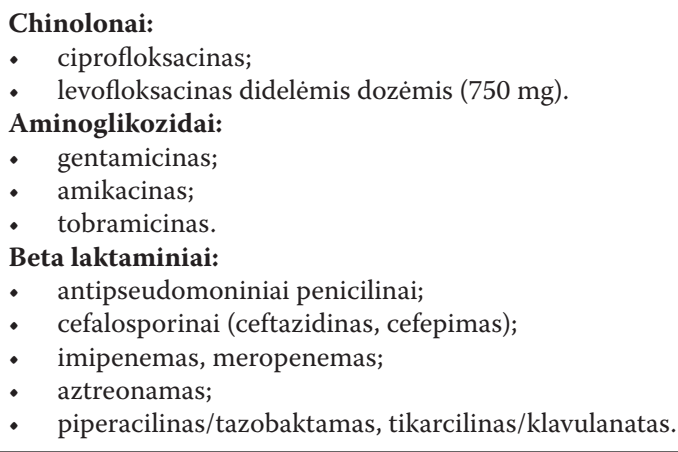

\section{ANTIBIOTICS IN THE TREATMENT OF SEVERE PATIENTS}

ARVYDAS VALAVIČIUS
DEPARTMENT OF PULMONOLOGY
KLAIPÉDA UNIVERSITY HOSPITAL

Key words: infection, antibiotics, dosage, penetration, purulent disease. Summary. Treatment of pneumonia, infectious diseases with antibiotics is discussed.

\section{LITERATŪRA}

1. Suaugusių ir vaiku pneumonijos diagnostika ir gydymas R. Sakalauskas ir kt. Medicina 2006.

2. Infectious diseases society of America / ATS nonsensus quidelines on the management of Comunity-Aquired pneumonia in adults. Lionel et al. CID 2007;44.

3. Quidelines for management of adults with HAP, VAP and health care associated pneumonia. AM J RESPIR CARE MED 2005. 